\title{
Dual 2-Hydroxypropyl- $\beta$-Cyclodextrin and 5,10,15,20-Tetrakis (4-Hydroxyphenyl) Porphyrin System as a Novel Chiral-Achiral Selector Complex for Enantioseparation of Aminoalkanol Derivatives with Anticancer Activity in Capillary Electrophoresis
}

\author{
Błażej Grodner ${ }^{1, *}$ and Mariola Napiórkowska ${ }^{2}$ (D) \\ 1 Chair and Department of Biochemistry and Pharmacogenomics, Medical University of Warsaw, \\ 1 Banacha Str., 02-097 Warsaw, Poland \\ 2 Chair and Department of Biochemistry, Medical University of Warsaw, 1 Banacha Str., 02-097 Warsaw, Poland; \\ mariola.napiorkowska@wum.edu.pl \\ * Correspondence: blazej_am@yahoo.com or bgrodner@wum.edu
}

Citation: Grodner, B.;

Napiórkowska, M. Dual

2-Hydroxypropyl- $\beta$-Cyclodextrin and 5,10,15,20-Tetrakis

(4-Hydroxyphenyl) Porphyrin System

as a Novel Chiral-Achiral Selector

Complex for Enantioseparation of

Aminoalkanol Derivatives with

Anticancer Activity in Capillary

Electrophoresis. Molecules 2021, 26,

993. https://doi.org/10.3390/

molecules26040993

Academic Editor: Loredana Salerno

Received: 28 December 2020

Accepted: 9 February 2021

Published: 13 February 2021

Publisher's Note: MDPI stays neutral with regard to jurisdictional claims in published maps and institutional affiliations.

Copyright: (c) 2021 by the authors. Licensee MDPI, Basel, Switzerland. This article is an open access article distributed under the terms and conditions of the Creative Commons Attribution (CC BY) license (https:/ / creativecommons.org/licenses/by/ $4.0 /$ )

\begin{abstract}
In this study, a complex consisting of 2-hydroxypropyl- $\beta$-cyclodextrin and 5,10,15,20tetrakis (4-hydroxyphenyl) porphyrin, (named dual chiral-achiral selector complex) was used for the determination of two novel potential anticancer agents of (I) and (II) aminoalkanol derivatives. This work aimed at developing an effective method that can be utilized for the determination of I (S), I (R), and II (S) and II (R) enantiomers of (I) and (II) compounds through the use of a dual chiral-achiral selector complex consisting of hydroxypropyl- $\beta$-cyclodextrin and 5,10,15,20-tetrakis (4-hydroxyphenyl) porphyrin system by applying capillary electrophoresis. This combination proved to be beneficial in achieving high separation selectivity due to the combined effects of different modes of chiral discrimination. The enantiomers of (I) and (II) compounds were separated within a very short time of 3.6-7.2 min, in $\mathrm{pH} 2.5$ phosphate buffer containing 2-hydroxypropyl- $\beta$-cyclodextrin and 5,10,15,20-tetrakis (4-hydroxyphenyl) porphyrin system at a concentration of 5 and $10 \mathrm{mM}$, respectively, at $25{ }^{\circ} \mathrm{C}$ and $+10 \mathrm{kV}$. The detection wavelength of the detector was set at $200 \mathrm{~nm}$. The LOD for I (S), I (R), II (S), and II (R) was 65.2, 65.6, 65.1, and $65.7 \mathrm{ng} / \mathrm{mL}$, respectively. LOQ for I (S), I (R), II (S), and II (R) was 216.5, 217.8, 217.1, and $218.1 \mathrm{ng} / \mathrm{mL}$, respectively. Recovery was $94.9-99.9 \%$. The repeatability and reproducibility of the method based on the values of the migration time, and the area under the peak was $0.3-2.9 \%$ RSD. The stability of the method was determined at $0.1-4.9 \%$ RSD. The developed method was used in the pilot studies for determining the enantiomers I (S), I (R), II (S), and II (R) in the blood serum.
\end{abstract}

Keywords: anticancer drug; capillary electrophoresis; chiral selectors; drug monitoring

\section{Introduction}

Separation of chiral compounds is very important in medical and pharmaceutical research as it allows studying the content of individual enantiomers in drugs and their concentrations in the human body and thus to determine the pharmacokinetic and pharmacodynamic parameters. Chiral compounds play a major role in drug-receptor interactions, in which one enantiomer of a racemic pair confers the desired pharmacological activity, while the other may exhibit negative side effects in the worst case [1-3]. In chiral compounds, numerous drugs, which have one or multiple asymmetric centers, occur as an enantiomer pair [4-10]. Therefore, it is necessary for the researchers to have knowledge of the composition of enantiomeric medicinal substances [11]. The most popular technique used for the determination of biological substances is the high-performance liquid chromatography. However, capillary electrophoresis (CE) is becoming an appealing alternative 
as it possesses a number of benefits such as high-speed analysis, low sample consumption, and high separation efficiency. $C E$ has already been demonstrated to have high potential in chiral separations [12], yielding very good results in the analyses of various pharmaceutically active substances. As we know, interactions occurring between chiral selectors and an enantiomer are the basis for separation in CE. For achieving effective chiral separation in $\mathrm{CE}$, the chiral selector should be added to the run buffer. Among the great variety of compounds that can be used as a chiral selector in CE are cyclodextrins (CDs), antibiotics, crown ethers, cyclofructans, and polysaccharides. CDs are one of the most commonly used chiral selectors [13-15]. Antibiotics [16-21], CD derivatives [22-27], chiral ligand exchangers [28-34], crown ethers [35-38], polysaccharides [39-42], and proteins [43-45] have also been employed depending on the properties of the enantiomers to be separated.

This study aimed to develop a new CE method characterized by high sensitivity and having the potential for rapid separation of the enantiomers I(R), I(S), and II(R), II(S) of the patented 4-[2-hydroxy-3-(propan-2-ylamino)propyl]-1,7-diethyl-8,9-diphenyl-4azatricyclo-[5.2.1.02,6]dec-8-ene-3,5,10-trione hydrochloride (I) and 4-[3-(dimethylamino)-2hydroxypropyl]-1,7-diethyl-8,9-diphenyl-4-azatricyclo[5.2.1.02,6]dec-8-ene-3,5,10-trione hydrochloride (II) (Figure 1) exhibiting anticancer activity [46].<smiles>C=C1C(=O)C2(CC)C(c3ccccc3)=C(c3ccccc3)C1C1C(=C)CC(=O)C12</smiles><smiles>CC(C)NCC(O)CN(C=O)C=O</smiles>

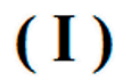<smiles></smiles>

\section{( II )}

Figure 1. Chemical structures of 4-[2-hydroxy-3-(propan-2-ylamino)propyl]-1,7-diethyl-8,9diphenyl-4-azatricyclo-[5.2.1.0 $0^{2,6}$ ]dec-8-ene-3,5,10-trione hydrochloride (I) and 4-[3-(dimethylamino)2-hydroxypropyl]-1,7-diethyl-8,9-diphenyl-4-azatricyclo[5.2.1.02,6]dec-8-ene-3,5,10-trione hydrochloride (II).

These compounds came from research into the cytotoxicity and anticancer properties notificated in a patent in 2012 [46]. Determination of compounds (I) and (II) using a CD derivative as a chiral selector has already been described in the previous work [47]. In the present study, we used the dual 2-hydroxypropyl- $\beta$-cyclodextrin and 5,10,15,20-tetrakis (4-hydroxyphenyl) porphyrin (Figure 2) chiral-achiral selector complex to investigate the combined effect of these two types of selectors on the enantioseparation of the model compounds. The developed method was found to be very effective and was used in the pilot studies for the determination of enantiomers in the blood serum. 
A

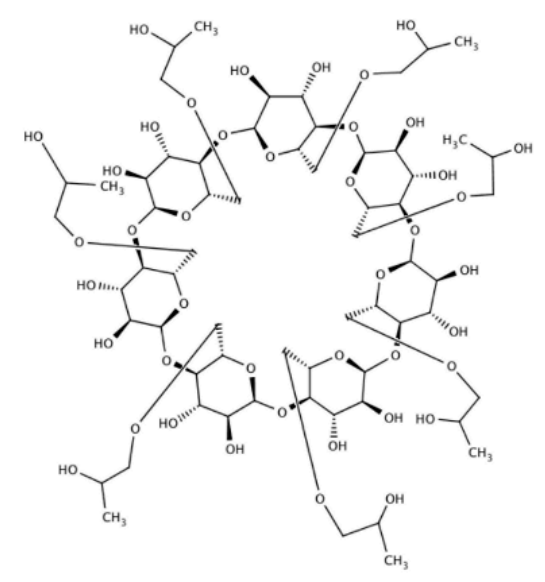

B

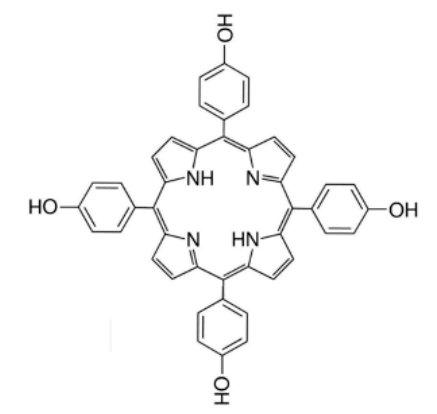

Figure 2. Chemical structures of 2-hydroxypropyl- $\beta$-cyclodextrin (A), 5,10,15,20-tetrakis (4hydroxyphenyl) porphyrin (B).

\section{Materials and Methods}

\subsection{Chemicals and Reagents}

The synthesis of the compounds as well as their spectroscopic analysis (nuclear magnetic resonance and mass spectrometry) has been explained in patent application [46] The purity of reference compounds was greater than $98 \%$, while other analytes used in separations had 99\% purity [47]. Phosphate buffer used in the study was obtained from Beckman-Coulter (Brea, USA), while the other chemicals were purchased from SigmaAldrich: $\gamma^{-}, \alpha-, \beta-$, and 2-hydroxypropyl- $\beta$-cyclodextrin (St. Louis, USA); deionized water and 5,10,15,20-tetrakis (4-hydroxyphenyl) porphyrin (Darmstadt, Germany); and ethyl acetate and hexane (Steinheim, Germany). The serum samples were obtained from 10 healthy drug-free volunteers.

\subsection{Instrumentation}

A Beckman Coulter P/ACE MDQ CE system, which contained an autosampler as well as a UV/Visible detector, was used for the separation. Karat software version 32 was used for controlling the CE parameters [47]. An eCAP fused-silica capillary (total length: $30 \mathrm{~cm}$, effective length: $20 \mathrm{~cm}$, ID: $50 \mu \mathrm{m}$, OD: $375 \mu \mathrm{m}$ ) was employed.

\subsection{Sample Preparation}

Stock solutions for the I $(S), \mathbf{I}(R)$, and II $(S)$ and II $(R)$ enantiomers, at the concentration of $10,000 \mathrm{ng} / \mathrm{mL}$ were prepared by dissolving of these substances in methanol. Then, from these solutions, calibration solutions with specific concentrations were prepared. These solutions were stored at $-15^{\circ} \mathrm{C}$. The analytes were found to be stable in the solution for around 30 days in the previous studies. Samples for the preparation of the working standards and the quality controls were prepared from the serum obtained from 10 healthy drug-free volunteers. The calibration solutions of 50,100,500,1000,5000, and 10,000 ng/mL were prepared in water and in serum, by adding appropriate amounts of the analyte stock solutions to the blank serum samples. Serum from healthy volunteers was a medium for dilution of the compounds and did not contain the tested compounds. As described previously [47], extraction was carried out with $500 \mu \mathrm{L}$ of serum, $100 \mu \mathrm{L}$ of I $(S)$ and I $(R)$, $100 \mu \mathrm{L}$ of II $(S)$ and II $(R)$, and $5 \mathrm{~mL}$ of the $n$-hexane-ethyl acetate mixture $(90: 10, \% v / v)$. These solutions were mixed and shaken well for around $4 \mathrm{~min}$. After centrifugation (at $5 \mathrm{~min}, 1000 \times g)$, the organic layer was removed and subjected to evaporation under a nitrogen stream at $37^{\circ} \mathrm{C}$. Then, the obtained sample was mixed with deionized water $(100 \mu \mathrm{L})$ and introduced on the capillary [47]. 


\subsection{CE Conditions}

Electrophoretic separations were carried out in the eCAP fused-silica capillary (total length: $30 \mathrm{~cm}$, effective length: $20 \mathrm{~cm}$, ID: $50 \mu \mathrm{m}$, OD: $375 \mu \mathrm{m}$ ) [47]. The enantiomers I (S), I $(R)$, II $(S)$, and II $(R)$ were analyzed with sodium dihydrogen phosphate $(25 \mathrm{mM})$, which contained 2-hydroxypropyl- $\beta$-cyclodextrin and 5,10,15,20-tetrakis (4-hydroxyphenyl) porphyrin system at a concentration of 5 and $10 \mathrm{mM}$, respectively, as background electrolyte (BGE); the system was adjusted to a $\mathrm{pH}$ of 2.5 by adding phosphoric acid. The parameters of the detector were set as follows: Wavelength: $200 \mathrm{~nm}$, temperature: $25^{\circ} \mathrm{C}$, and voltage: $+10 \mathrm{kV}$.

New capillaries were flushed with $1 \mathrm{M} \mathrm{NaOH}$ (15 min, $10 \mathrm{psi})$, water (15 min, $10 \mathrm{psi})$, and BGE (20 min, 10 psi). Finally, the system was electroconditioned with the running buffer by applying the separation voltage $(+10 \mathrm{kV})$ for $20 \mathrm{~min}$. Between workdays, the capillary was conditioned by rinsing successively with $0.1 \mathrm{M} \mathrm{NaOH}$ ( $5 \mathrm{~min}, 10 \mathrm{psi}$ ), water (5 min, $10 \mathrm{psi})$, and BGE (10 min, $10 \mathrm{psi})$. Samples were hydrodynamically injected at a pressure of 2 psi for $6 \mathrm{~s}$. A separation voltage of $10 \mathrm{kV}$ (normal polarity anode at the injection capillary end) was applied for performing the electrophoretic separations at $25^{\circ} \mathrm{C}$. Between runs, the capillary was rinsed for $2 \mathrm{~min}$ with water and for 3 min with BGE. At the end of every analysis, the working BGE was refreshed to ensure optimum separation repeatability. After extraction with $n$-hexane-ethyl acetate mixture $(90: 10, \% v / v)$ and dissolving in $0.1 \mathrm{~mL}$ of aqueous solution, the serum samples were injected automatically using pressure ( 2 psi on sample solution for $5 \mathrm{~s}$ ). The vials having both cathode and anode buffers were emptied late in the day, and the running buffer was refilled at the start of the following working day, before analysis, as indicated by the earlier described procedure [47].

\section{Results and Discussion}

\subsection{Optimization}

In this study, three kinds of CDs, namely 2-hydroxypropyl- $\alpha$-cyclodextrin, 2-hydroxypropyl$\beta$-cyclodextrin, and 2-hydroxypropyl- $\gamma$-cyclodextrin, and one porphyrin derivative $(5,10,15,20$ tetrakis (4-hydroxyphenyl) porphyrin) were screened at different $\mathrm{pH}$ values as potential chiral selector candidates, either alone or in combinations. Among the tested CDs, only 2-hydroxypropyl$\beta$-cyclodextrin allowed a baseline separation of the enantiomers of compounds (I) and (II). The best results were achieved when 2-hydroxypropyl- $\beta$-cyclodextrin was used at a concentration of $5 \mathrm{mM}$ (Figure 3A). Other phosphate buffers, containing 2-hydroxypropyl- $\alpha$ cyclodextrin and 2-hydroxypropyl- $\gamma$-cyclodextrin at a concentration of $5 \mathrm{mM}$, did not allow satisfactory separation of compounds (I) and (II) into individual enantiomers. Therefore, for the initial separation of the enantiomers I $(S), \mathbf{I}(R)$, II $(S)$, and II $(R)$, 2-hydroxypropyl$\beta$-cyclodextrin was chosen as the first chiral selector.

The resolution was tested by introducing the second selector-(5,10,15,20-tetrakis (4hydroxyphenyl) porphyrin) into the system. Maintaining the concentration of 2-hydroxypropyl- $\beta$ cyclodextrin in the tested system at $5 \mathrm{mM}$, the concentration of 5,10,15,20-tetrakis (4-hydroxyphenyl) porphyrin was gradually increased while examining the resolution of the enantiomers $\mathbf{I}(S), \mathbf{I}(R)$, II $(S)$, and II $(R)$. The best resolution and absorbance were achieved for the system containing 2-hydroxypropyl- $\beta$-cyclodextrin at a concentration of $5 \mathrm{mM}$ and 5,10,15,20-tetrakis (4-hydroxyphenyl) porphyrin at a concentration of $10 \mathrm{mM}$ (Figure 4). 

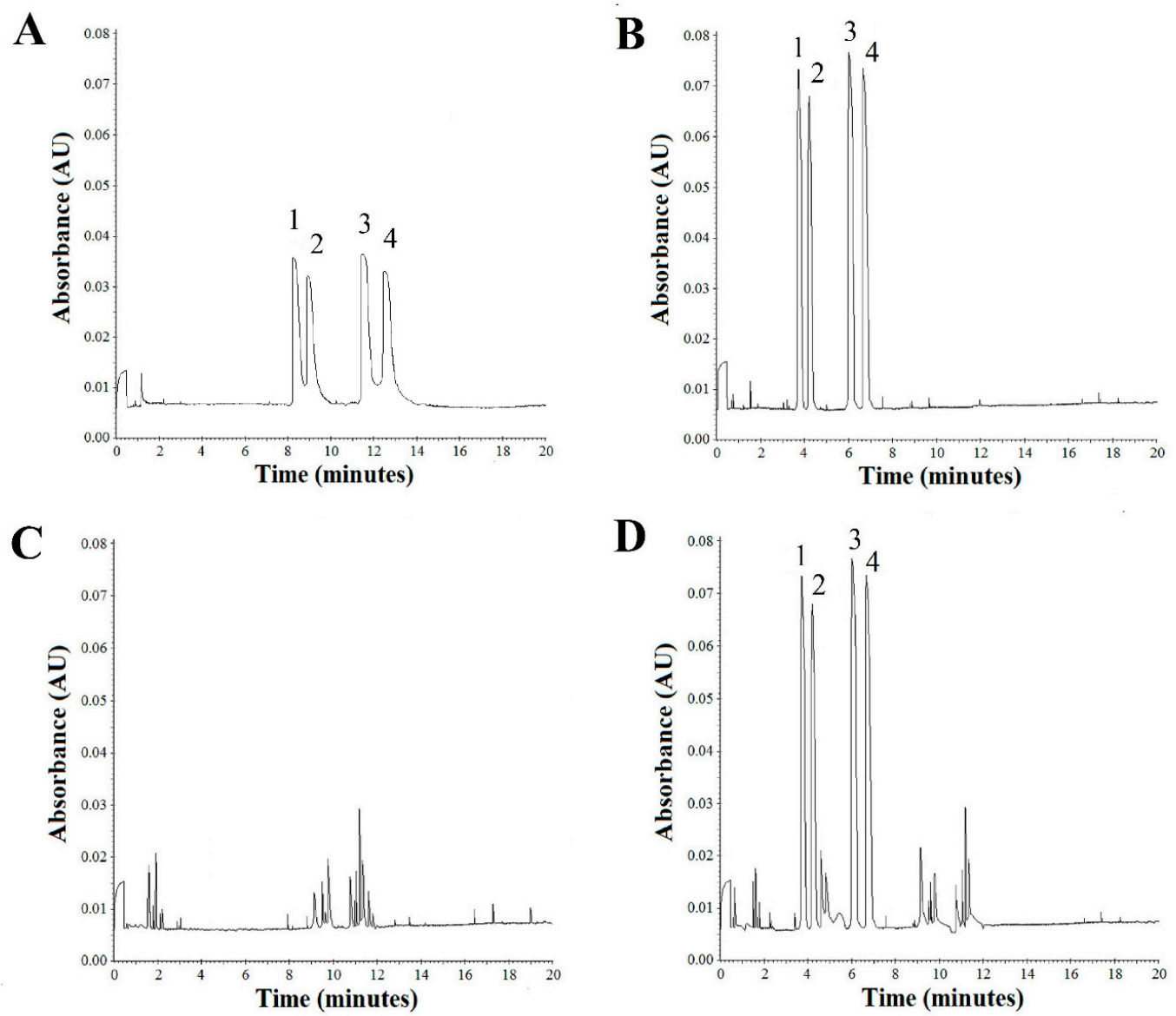

Figure 3. Separation of the (1) I (S), (2) I (R), (3) II (S), and (4) II (R) enantiomers in the $25 \mathrm{mM}$ phosphate buffer of pH 2.5 containing 2-hydroxypropyl- $\beta$-cyclodextrin (A), 2-hydroxypropyl- $\beta$-cyclodextrin and 5,10,15,20-tetrakis (4-hydroxyphenyl) porphyrin system at the concentration of 5 and $10 \mathrm{mM}$, respectively (B), blank serum (C), and serum with addition of $\mathbf{I}(S)$, I $(R)$ and II $(S)$, II $(R)$ enantiomers of the aminoalkanol derivatives (D).

The average detection times for I $(S), \mathbf{I}(R)$, II $(S)$, and II $(R)$ were $3.60,4.08,5.88$, and $6.61 \mathrm{~min}$, respectively (Figure 3B).

The combination of CDs with 5,10,15,20-tetrakis (4-hydroxyphenyl) porphyrin used as the second selector significantly improved the separation conditions such as time, resolution, and sensitivity for both the enantiomers of the compounds (I) and (II) (Figure 3B). The resolution presented in the Figures 4-8 was calculated based on the migration time ratios for I $(S), \mathbf{I}(R)$, and II $(S)$, II $(R)$ according to the equations: equations:

$$
\alpha 1=\frac{t m I(R)}{t m I(S)} \text { and } \alpha 2=\frac{t m I I(R)}{t m I I(S)}
$$

where: $\alpha$-resolution; $\mathrm{tm} \mathbf{I}(R)$-migration time of compound I $(R)$ [min]; $\mathrm{tm} \mathbf{I}(S)$-migration time of compound I $(S)$ [min]; tm II $(R)$-migration time of compound II $(R)$ [min]; tm II $(S)$-migration time of compound II (S) [min]. 


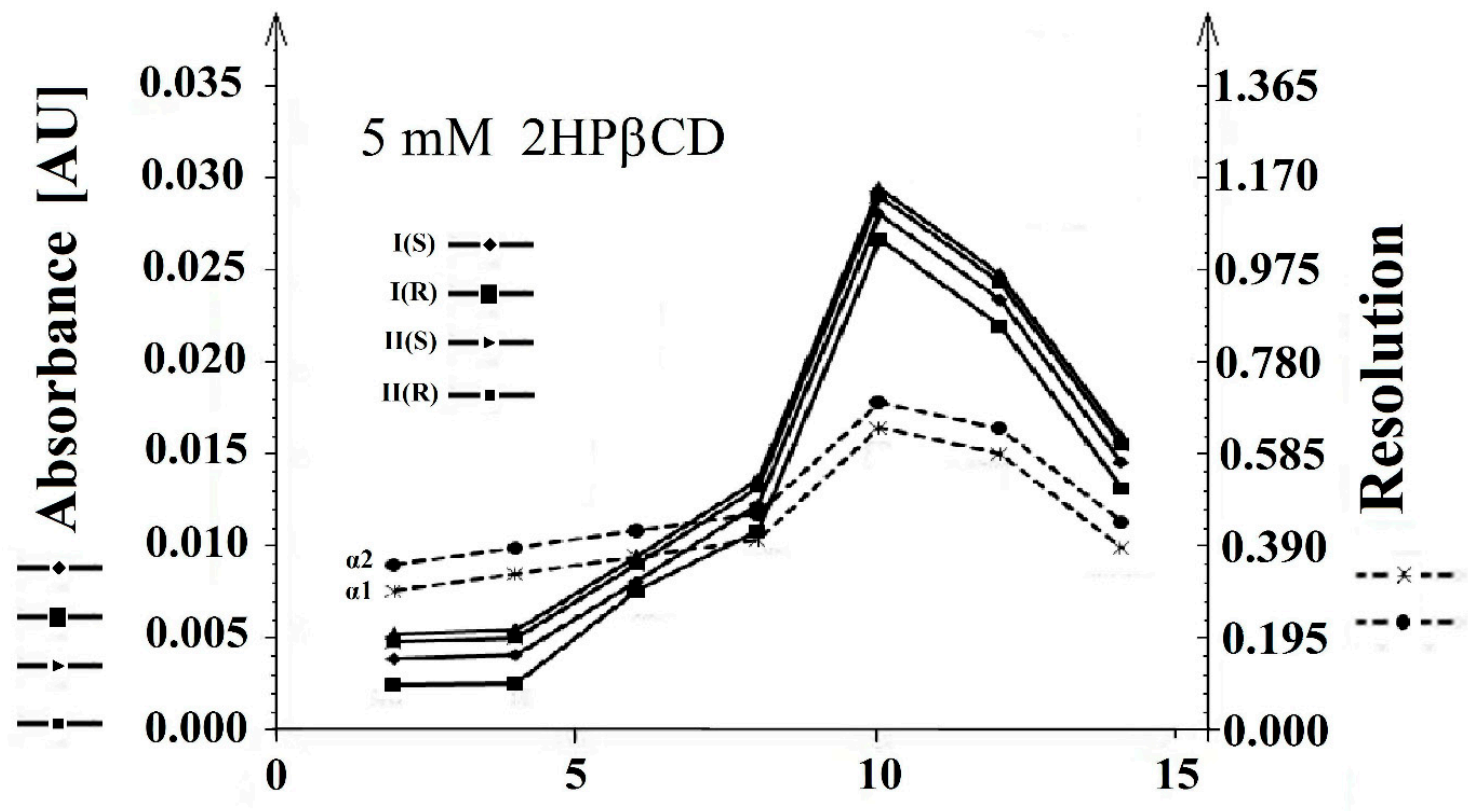

\section{Concentration of porphyrine derivate $[\mathrm{mM}]$}

Figure 4. The influence of the concentration of 5,10,15,20-tetrakis (4-hydroxyphenyl) porphyrin at a constant concentration of 2-hydroxypropyl- $\beta$-cyclodextrin $(2 \mathrm{HP} \beta \mathrm{CD})(5 \mathrm{mM})$ on the resolution $(\alpha 1$ and $\alpha 2)$ and absorbance (AU) of the I $(S), \mathbf{I}(R)$ and II $(S)$, II $(R)$ enantiomers.

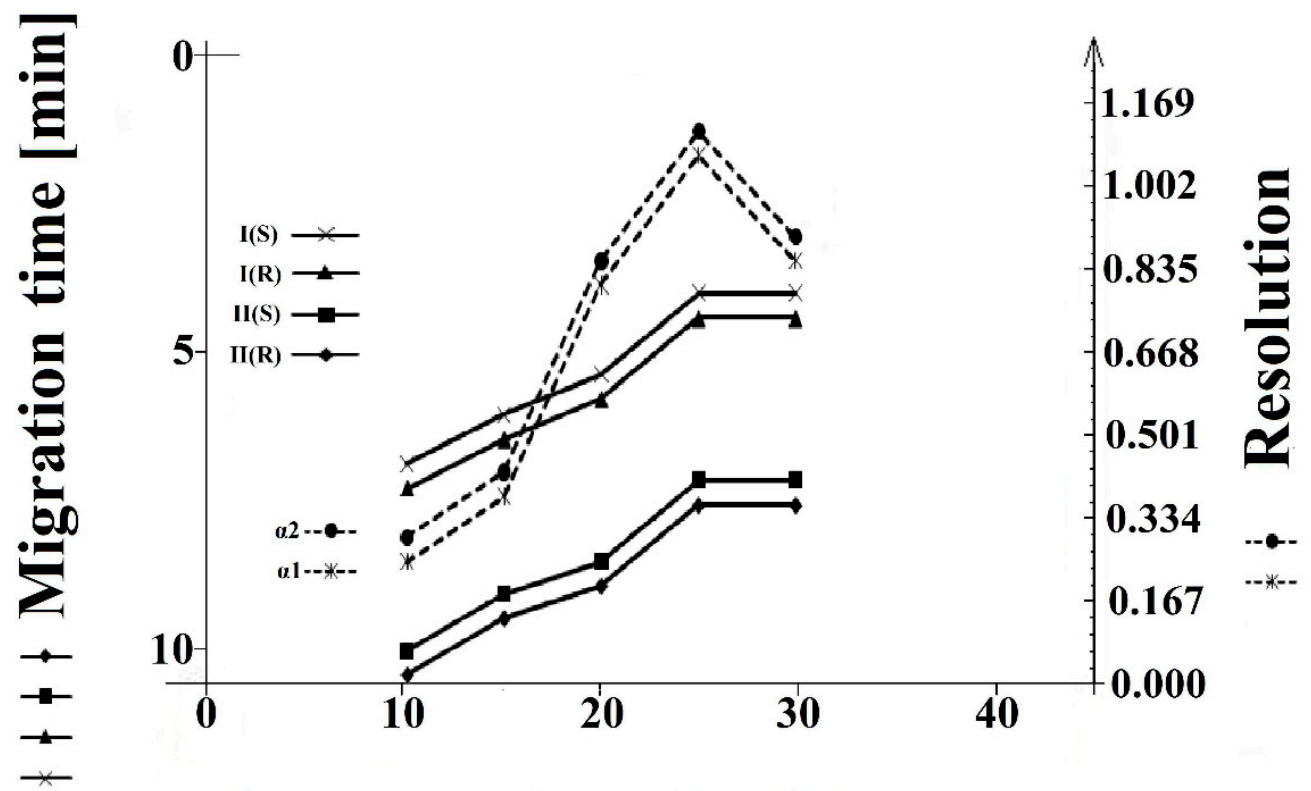

Concentration of BGE $[\mathrm{mM}]$

Figure 5. The influence of the concentration of background electrolyte buffer on the resolution $(\alpha 1$ and $\alpha 2)$ and migration time of the I $(S), \mathbf{I}(R)$, and II $(S)$, II $(R)$ enantiomers. 


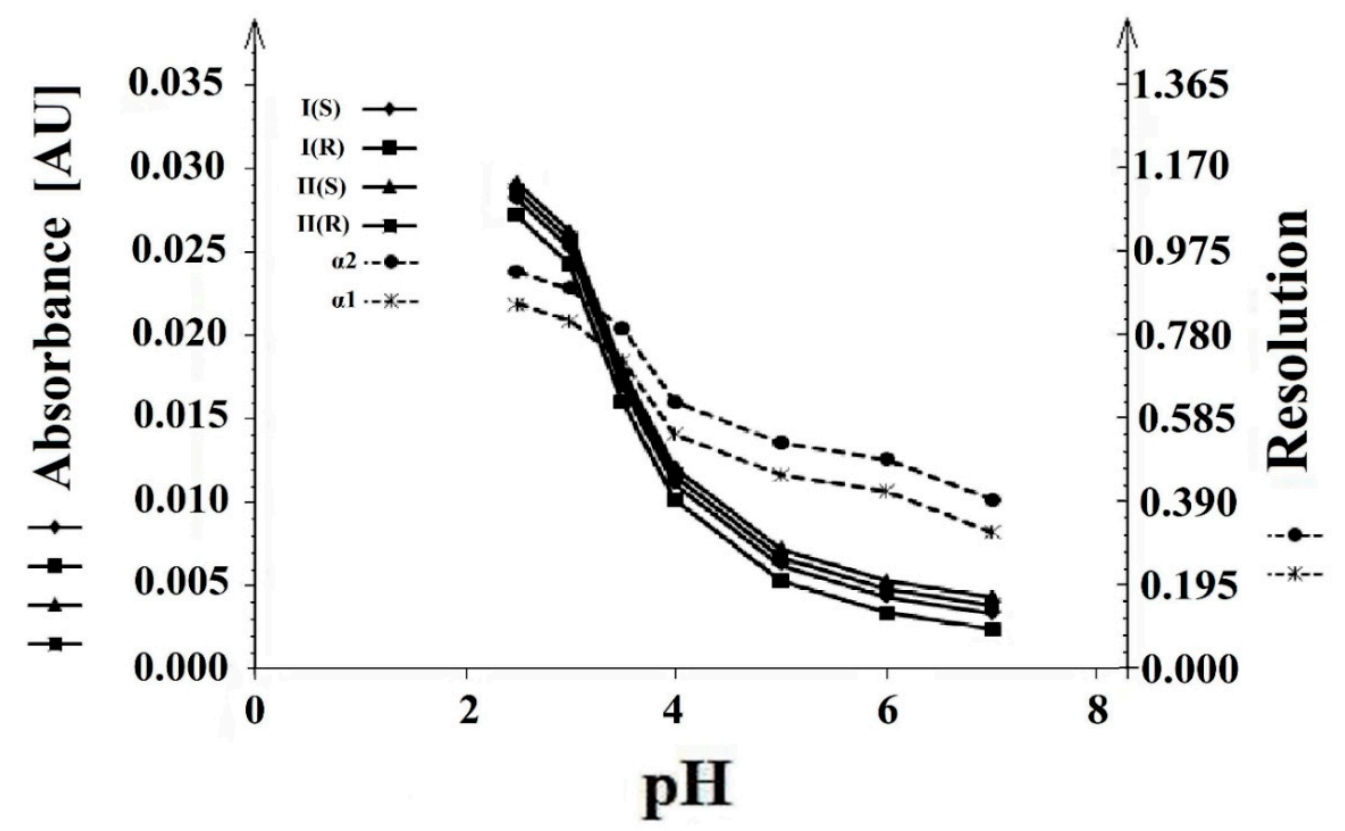

Figure 6. The influence of the $\mathrm{pH}$ buffer on the resolution ( $\alpha 1$ and $\alpha 2)$ and absorbance (AU) of the I (S), I (R), and II (S), II $(R)$ enantiomers.

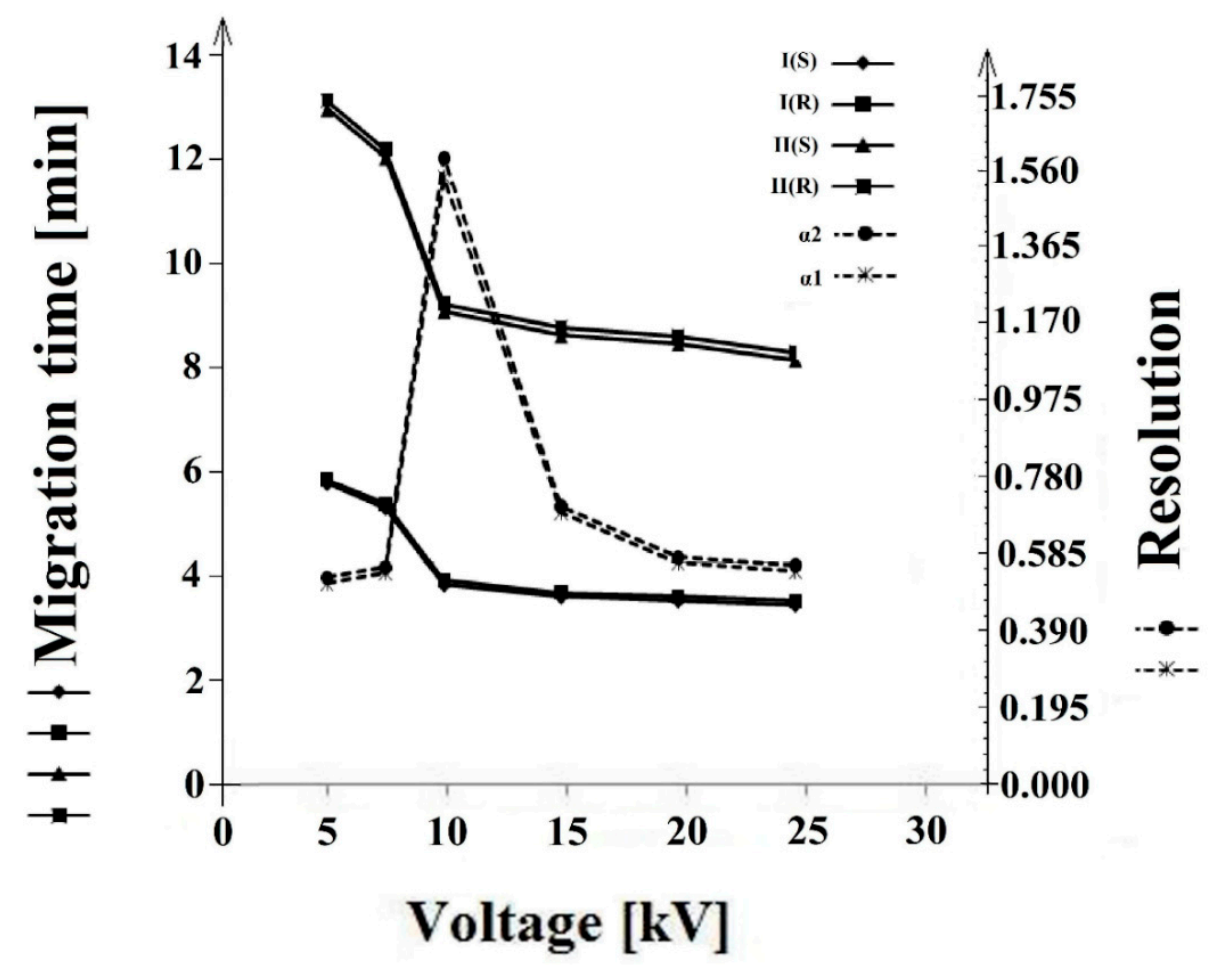

Figure 7. The influence of the voltage $(\mathrm{kV})$ on the resolution $(\alpha 1$ and $\alpha 2)$ and migration time of the I $(S)$, I (R), and II (S), II (R) enantiomers. 


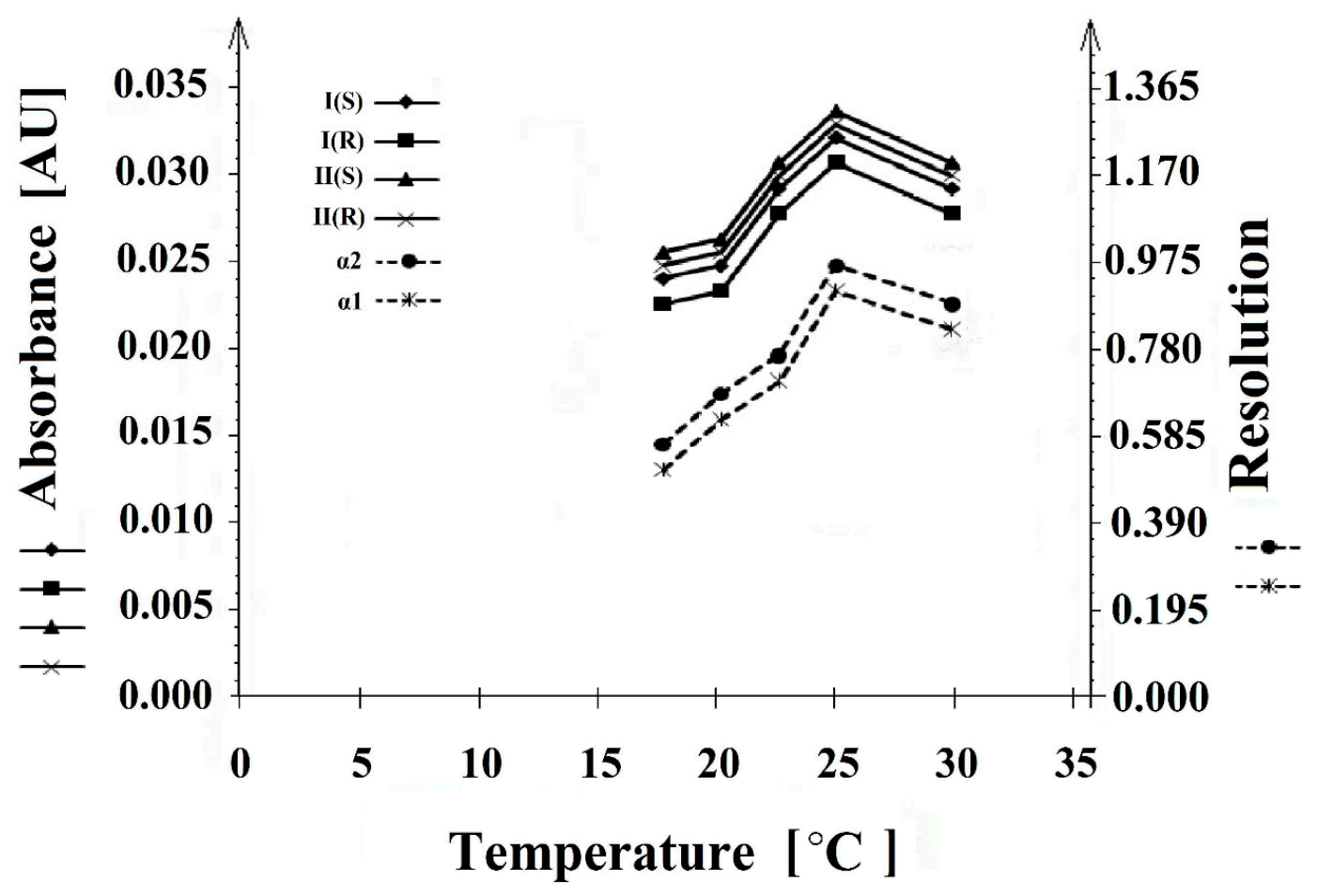

Figure 8. The influence of the temperature (T) on the resolution ( $\alpha 1$ and $\alpha 2)$ and migration time of the I (S), I $(R)$, and II (S), II $(R)$ enantiomers.

The influence of BGE concentration on the resolution and migration time was investigated at 10,15,20,25, and $30 \mathrm{mM}$. As the concentration of phosphate buffer increased, the resolution increased, the peak shapes sharpened, and the migration time of the determined compounds I $(S), \mathbf{I}(R)$, II $(S)$, and II $(R)$ decreased. The best results were observed at the concentration of $25 \mathrm{mM}$ (Figure 5).

Considering the resolution, peak shape, and migration times of (I) and (II) compounds, the final BGE conditions were determined as follows: concentration: $25 \mathrm{mM}$ and $\mathrm{pH}$ : 2.5.

The effect of $\mathrm{pH}$ on the separation process was analyzed at $\mathrm{pH}$ values from 7.0 to 2.5. A decrease in $\mathrm{pH}$ led to an increase in the resolution between (I) and (II) enantiomers. At $\mathrm{pH} 7.0$, no resolution was found between the tested compounds. At $\mathrm{pH} 3.5$, the resolution was insufficient between derivatives I $(S), \mathbf{I}(R)$, and II $(S), \mathbf{I I}(R)$. The best resolution and absorbance of these compounds were observed with phosphate buffer at a concentration of $25 \mathrm{mM}$ and $\mathrm{pH} 2.5$ (Figure 6).

The influence of voltage on the separation and migration time was assessed at 5, 7, 10, 15,20 , and $25 \mathrm{kV}$. An increase in voltage to $10 \mathrm{kV}$ increased the resolution. After $10 \mathrm{kV}$ was exceeded, the resolution decreased, while the migration time decreased with the increasing voltage (Figure 7).

The influence of the temperature of the separation process was investigated at 18, 20, 22,25 , and $30^{\circ} \mathrm{C}$. An increase in the temperature caused an increase in absorbance and resolution. The best results were achieved at $25^{\circ} \mathrm{C}$ (Figure 8 ).

Because the best separation of I $(S), \mathbf{I}(R)$, II $(S)$, and II $(R)$ was achieved using 2hydroxypropyl- $\beta$-cyclodextrin and 5,10,15,20-tetrakis (4-hydroxyphenyl) porphyrin system at concentrations of 5 and $10 \mathrm{mM}$, respectively, in $25 \mathrm{mM}$ phosphate buffer at a $\mathrm{pH}$ of 2.5 , separation voltage of $10 \mathrm{kV}$, and temperature of $25^{\circ} \mathrm{C}$, this method was used for the preliminary studies of the enantiomers I $(S), \mathbf{I}(R)$, and II $(S)$ and II $(R)$ of the newly patented aminoalkanol derivatives in the blood serum (Figure 3D). 


\subsection{Method Development}

CE enables us to selectively monitor I $(S), \mathbf{I}(R)$, and II $(S)$ and II $(R)$ and to eliminate interference with the endogenous components that can be co-eluted from serum samples. The enantiomers I (S), I (R), and II $(S)$, II $(R)$ were separated using 2-hydroxypropyl- $\beta$ cyclodextrin and 5,10,15,20-tetrakis (4-hydroxyphenyl) porphyrin system at the concentration of 5 and $10 \mathrm{mM}$, respectively. For developing this method as well as determining the validation parameters, the buffer $\mathrm{pH}$, separating BGE concentration, chiral selector concentration, concentration and composition of extraction phase, wavelength, voltage, and temperature were optimized. During extraction, $500 \mu \mathrm{L}$ of the serum solution was added in a glass tube, followed by which $100 \mu \mathrm{L}$ of $\mathbf{I}(S)$ and $\mathbf{I}(R)$ and $100 \mu \mathrm{L}$ of $\mathbf{I I}(S)$ and II $(R)$ were added, and the solutions were mixed together. The mixture was set aside for $5 \mathrm{~min}$, and then, $5 \mathrm{~mL}$ of extraction solvent ( $n$-hexane-ethyl acetate, 90:10, \% v/v) was added. The mixture was shaken vigorously (vortexed) for $4 \mathrm{~min}$. Subsequently, the mixture was centrifuged for $4 \mathrm{~min}$ at $1000 \times \mathrm{g}$. After centrifugation, the separated organic layer was removed and added to another glass tube, and was placed in a heating mantle, at a temperature of $37^{\circ} \mathrm{C}$. Then, it was subjected to evaporation at $37^{\circ} \mathrm{C}$ under a nitrogen stream. The obtained residue was mixed with deionized water at $37^{\circ} \mathrm{C}$. Finally, the dissolved sample was moved to a capillary vial and then injected on the capillary. In this study, phosphate buffer containing 2-hydroxypropyl- $\beta$-cyclodextrin and 5,10,15,20-tetrakis (4-hydroxyphenyl) porphyrin system at a concentration of 5 and $10 \mathrm{mM}$, respectively, was chosen as a BGE because of its good separation performance. Considering the analysis time and resolution comprehensively, $+10 \mathrm{kV}$ was chosen as the separation voltage. Based on the above study, CE was applied for separation, with the separation conditions set as follows: BGE: $25 \mathrm{mM}$ phosphate buffer at $\mathrm{pH} 2.5$ containing 2-hydroxypropyl- $\beta$-cyclodextrin and 5,10,15,20-tetrakis (4-hydroxyphenyl) porphyrin system at 5 and $10 \mathrm{mM}$, respectively; voltage: $+10 \mathrm{kV}$; detection temperature: $25^{\circ} \mathrm{C}$; and detection wavelength: $200 \mathrm{~nm}$. The measurements were performed with a fused-silica capillary (effective length: $20 \mathrm{~cm}$; diameter: $50 \mu \mathrm{m})$. The samples to be tested were hydrodynamically injected on the capillary [47]. Under these separation conditions, compounds (I) and (II) were eluted and separated in less than $7 \mathrm{~min}$. The peaks were identified by injecting individual analytes based on migration time matching.

The preliminary analysis of the studied drugs exhibiting biological activity is described elsewhere [46,47]. The extraction procedure developed in this study required using an extraction solvent made of $n$-hexane and ethyl acetate, in 90:10 (\%v/v) proportions. The optimum time of sample shaking was determined as $4 \mathrm{~min}$. Appropriate organic layer separation was performed by centrifuging at $1000 \times \mathrm{g}$ for $5 \mathrm{~min}$. The separated organic layer was subjected to evaporation under a nitrogen stream at $37^{\circ} \mathrm{C}$. Deionized water was added to dissolve the samples, after which the samples were injected on the capillary. The developed extraction procedure is a simple, time-saving, and single-step process.

\subsection{Method Validation}

The linearity, precision, specificity, accuracy, carry-over extraction recoveries, and limit of detection (LOD) as well as limit of quantification (LOQ) of the developed method were validated by following the guidelines of the International Council on Harmonization (ICH) [48] and the previously presented procedure [47].

The first step before the validation process involved the screening of selectors, as described in Section 3.1. Optimization.

The specificity of the method was defined as its ability to differentiate and quantify an analyte of interest and an internal standard from the endogenous components in the matrix, or other components in the sample. The presence of potential endogenous interference was assessed by analyzing 10 serum samples obtained from the free-drug volunteers, which were fortified with the I $(S), \mathbf{I}(R)$, and II $(S)$, II $(R)$ compounds. The measurement results (Figure $3 C$ ) showed the absence of endogenous interferences for every analyte of interest. The LODs and LOQs were determined by measuring the I $(S), \mathbf{I}(R)$, and II $(S)$, II $(R)$ 
compounds in a series of decreasing concentrations in the serum samples. In line with the ICH guidelines, LODs were determined at the lowest concentrations of $\mathbf{I}(S), \mathbf{I}(R)$, and II $(S)$, II $(R)$, with a signal-to-noise ratio of at least 3 for all the compounds. The LOQ values were determined by quantitative measurement of the lowest compound concentration with a stated and acceptable accuracy and precision $(\mathrm{CV} \%<20)$. The LODs and LOQs were estimated by analyzing the fortified serum samples of $500 \mu \mathrm{L}$ volume. All the calibration curves indicated an excellent linear regression (with an $R^{2}$ of 0.9969-0.9998). The LOD values for I $(S)$, I $(R)$, II $(S)$, and II $(R)$ were estimated at $65.2,65.6,65.4$, and $65.7 \mathrm{ng} / \mathrm{mL}$, respectively, while the LOQ values for these compounds were 216.5, 217.8, 217.1, and $218.1 \mathrm{ng} / \mathrm{mL}$, respectively (Table 1 ).

Table 1. Regression equation, limits of detection, and quantification for compounds $\mathrm{I}(S), \mathrm{I}(R)$, and $\mathrm{II}(S), \mathrm{II}(R)(n=6)$.

\begin{tabular}{|c|c|c|c|c|c|c|c|c|}
\hline Compounds & $\begin{array}{l}\text { Linearity } \\
\text { Range }\end{array}$ & $\mathbf{R}^{2}$ & $\begin{array}{c}\text { (RSD) } \\
{[\%]}\end{array}$ & LOD & LOQ & $\begin{array}{c}\text { Regression } \\
\text { Equation }\end{array}$ & \multicolumn{2}{|c|}{$\underline{( \pm \mathrm{SD})}$} \\
\hline & $\mathrm{ng} / \mathrm{mL}$ & Mean & & $\mathrm{ng} / \mathrm{mL}$ & $\mathrm{ng} / \mathrm{mL}$ & Mean & Slope & Intercept \\
\hline $\mathbf{I}(S)$ & 200-10000 & 0.9998 & 1.62 & 65.2 & 216.5 & $y=51.80 x-1425$ & \pm 0.11 & \pm 5.41 \\
\hline $\mathbf{I}(R)$ & 200-10000 & 0.9979 & 2.17 & 65.6 & 217.8 & $y=51.81 x-1477$ & \pm 0.12 & \pm 6.13 \\
\hline $\mathbf{I I}(S)$ & 200-10000 & 0.9998 & 2.03 & 65.4 & 217.1 & $y=51.80 x-1415$ & \pm 0.11 & \pm 5.50 \\
\hline $\mathbf{I I}(R)$ & 200-10000 & 0.9969 & 2.23 & 65.7 & 218.1 & $y=49.68 x-994$ & \pm 0.14 & \pm 7.04 \\
\hline
\end{tabular}

RSD-Relative Standard Deviation; LOD-Limit Of Detection; LOQ-Limit Of Quantification.

Recovery of the compounds I $(S), \mathbf{I}(R), \mathbf{I I}(S)$, and II $(R)$ was assessed by comparing the mean relative peak area for the samples containing these compounds at three different levels of concentration (high, medium, and low) in relation to the true concentrations of the pure standards, with the mean relative peak area for those compounds after extraction from the matrix. The recoveries determined for the analytes from serum solution and water were satisfactory in a range of $94.6-99.9 \%$ (Table 2). The results presented in Table 2 show that the extraction method is suitable for measuring the drug levels in patients' serum.

The precision of the proposed method in terms of repeatability was determined by conducting a replicate analysis $(n=6)$ of serum extracts that were spiked with 100 and $1000 \mathrm{ng} / \mathrm{mL}$ of each compound. The relative standard deviation for migration time and relative peak area was less than $3.0 \%$ (Table 3).

Stability tests were performed under high-quality control. The analytes were stable in a serum blank at room temperature for $6 \mathrm{~h}$ and under repeated freeze-thaw conditions (totally three cycles). The samples to be tested were kept at $-25^{\circ} \mathrm{C}$ to evaluate their stability in a short-term experiment. The findings presented in Table 4 confirm the stability of the analytes for around 30 days. 
Table 2. Recovery data of compounds I and II from standard solutions (SL) $(n=6)$ and serum $(S)(n=6)$.

\begin{tabular}{|c|c|c|c|c|c|c|c|c|c|}
\hline Compounds & Added Amount & Observed Amount & \%Recovery & $\%$ RSD & Compounds & Added Amount & Observed Amount & \%Recovery & $\%$ RDS \\
\hline & & $\underline{\text { Mean } \pm \text { SD }}$ & & & & & $\underline{\text { Mean } \pm \text { SD }}$ & & \\
\hline (SL) & $\mathrm{ng} / \mathrm{mL}$ & $\mathrm{ng} / \mathrm{mL}$ & & & (S) & $\mathrm{ng} / \mathrm{mL}$ & $\mathrm{ng} / \mathrm{mL}$ & & \\
\hline \multirow{2}{*}{ I $(S)$} & 500 & $495.2 \pm 2.7$ & 99.4 & 0.5 & & 500 & $496.7 \pm 3.4$ & 99.3 & 0.7 \\
\hline & 1000 & $998.9 \pm 1.2$ & 99.9 & 0.1 & & 1000 & $997.9 \pm 2.2$ & 99.8 & 0.2 \\
\hline \multirow[t]{3}{*}{$\mathbf{I}(R)$} & 100 & $97.8 \pm 3.9$ & 97.8 & 4.0 & $\mathbf{I}(R)$ & 100 & $94.9 \pm 5.9$ & 94.9 & 6.2 \\
\hline & 500 & $496.9 \pm 3.1$ & 99.4 & 0.6 & & 500 & $497.1 \pm 2.9$ & 99.4 & 0.6 \\
\hline & 1000 & $997.7 \pm 1.6$ & 99.8 & 0.2 & & 1000 & $996.8 \pm 3.3$ & 99.7 & 0.3 \\
\hline \multirow[t]{3}{*}{ II $(S)$} & 100 & $97.4 \pm 3.7$ & 97.4 & 3.8 & II $(S)$ & 100 & $95.3 \pm 4.9$ & 95.3 & 5.1 \\
\hline & 500 & $495.0 \pm 2.9$ & 99.0 & 0.6 & & 500 & $498.6 \pm 1.4$ & 99.7 & 0.3 \\
\hline & 1000 & $998.0 \pm 1.5$ & 99.8 & 0.2 & & 1000 & $998.7 \pm 1.3$ & 99.9 & 0.1 \\
\hline \multirow[t]{3}{*}{ II $(R)$} & 100 & $97.6 \pm 3.4$ & 97.6 & 3.5 & II $(R)$ & 100 & $94.6 \pm 5.5$ & 94.6 & 5.8 \\
\hline & 500 & $496.0 \pm 2.9$ & 99.2 & 0.6 & & 500 & $496.5 \pm 3.6$ & 99.3 & 0.7 \\
\hline & 1000 & $997.0 \pm 2.2$ & 99.7 & 0.2 & & 1000 & $997.1 \pm 3.0$ & 99.7 & 0.3 \\
\hline
\end{tabular}


Table 3. Intra-day and inter-day precision of compounds I (S), I (R) and II (S), II (R) analytes.

\begin{tabular}{|c|c|c|c|c|c|c|c|c|c|}
\hline \multirow[t]{3}{*}{ Compounds } & \multirow{3}{*}{$\frac{\text { Concentration }}{\mathrm{ng} / \mathrm{mL}}$} & \multicolumn{3}{|c|}{ Intra-Day Precision ( $n=6$, Mean) } & \multirow{2}{*}{\multicolumn{5}{|c|}{$\frac{\text { Inter-Dday Precision }}{(n=18, \text { mean })}$}} \\
\hline & & \multirow{2}{*}{$\frac{\text { Day-1 }}{t_{\mathrm{m}} / \% \mathrm{RSD}}$} & \multirow{2}{*}{$\frac{\text { Day-2 }}{P_{\mathrm{A}} / \% \text { RSD }}$} & \multirow{2}{*}{$\frac{\text { Day-3 }}{t_{\mathrm{m}} / \% \text { RSD }}$} & & & & & \\
\hline & & & & & $P_{\mathrm{A}} / \% \mathrm{RSD}$ & $t_{\mathrm{m}} / \% \mathrm{RSD}$ & $P_{\mathrm{A}} / \% \mathrm{RSD}$ & $t_{\mathrm{m}} / \% \mathrm{RSD}$ & $P_{\mathrm{A}} / \% \mathrm{RSD}$ \\
\hline $\mathrm{I}(S)$ & 100 & $3.72 / 0.5$ & $1116 / 1.0$ & $3.79 / 0.5$ & $1138 / 1.0$ & $3.75 / 0.5$ & $1093 / 1.0$ & $3.75 / 1.1$ & $1116 / 2.0$ \\
\hline $\mathrm{I}(R)$ & 100 & $4.37 / 0.4$ & $1150 / 1.0$ & $4.39 / 0.7$ & $1172 / 1.0$ & $4.42 / 0.7$ & $1138 / 1.0$ & $4.39 / 0.7$ & $1153 / 1.5$ \\
\hline $\mathrm{II}(S)$ & 100 & $6.08 / 0.5$ & $1003 / 0.9$ & $6.12 / 0.5$ & $1116 / 1.0$ & $6.13 / 0.5$ & $1071 / 1.0$ & $6.11 / 0.5$ & $1063 / 2.9$ \\
\hline II $(R)$ & 100 & $7.23 / 0.6$ & $1195 / 1.1$ & $7.28 / 0.5$ & $1138 / 1.0$ & $7.25 / 0.6$ & $1161 / 1.0$ & $7.25 / 0.4$ & $1165 / 2.5$ \\
\hline $\mathrm{I}(S)$ & 1000 & $3.61 / 0.3$ & $12389 / 0.4$ & $3.67 / 0.3$ & $14247 / 0.5$ & $3.65 / 0.3$ & $13938 / 0.4$ & $3.64 / 0.8$ & $13525 / 0.5$ \\
\hline $\mathrm{I}(R)$ & 1000 & $4.16 / 0.2$ & $13938 / 0.4$ & $4.25 / 0.2$ & $14557 / 0.5$ & $4.23 / 0.2$ & $13628 / 0,4$ & $4.21 / 1.2$ & $14041 / 0.5$ \\
\hline II $(S)$ & 1000 & $5.90 / 0.2$ & $9911 / 0.3$ & $5.95 / 0.2$ & $11770 / 0.4$ & $5.98 / 0.3$ & $11150 / 0.4$ & $5.94 / 0.7$ & $10944 / 0.4$ \\
\hline II $(R)$ & 1000 & $7.00 / 0.3$ & $13628 / 0.4$ & $7.04 / 0.3$ & $13938 / 0.4$ & $7.08 / 0.3$ & $13318 / 0.4$ & $7.04 / 0.6$ & $13628 / 0.4$ \\
\hline
\end{tabular}

Table 4. Stability studies for compounds I (S), I $(R)$, and II $(S)$, II $(R)$.

\begin{tabular}{|c|c|c|c|c|c|c|c|}
\hline Spiked & Bench Top ${ }^{a}$ & Freeze and Thaw ${ }^{b}$ & & & Short Term ${ }^{c}$ & & \\
\hline \multicolumn{8}{|c|}{ Concentration } \\
\hline \multirow[t]{5}{*}{ (ng/mL) } & & - & & & 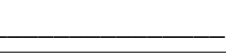 & & \\
\hline & Mean \pm SD & Mean \pm SD & & & Mean \pm SD & & \\
\hline & Obtained & $\%$ RSD & Obtained & $\%$ RSD & Obtained & $\%$ RSI & \\
\hline & Concentration & & Concentration & & Concentration & & \\
\hline & $(\mathrm{ng} / \mathrm{mL})^{\mathrm{d}}$ & $(\mathrm{ng} / \mathrm{mL})^{\mathrm{d}}$ & $(\mathrm{ng} / \mathrm{mL})^{\mathrm{d}}$ & & & & \\
\hline \multirow{2}{*}{$\mathbf{I}(S)$} & 100 & $98.8 \pm 3.2$ & 3.2 & $91.2 \pm 4.9$ & 5.4 & $100.9 \pm 4.9$ & 4.9 \\
\hline & 1000 & $999.0 \pm 1.3$ & 0.1 & $994.1 \pm 2.8$ & 0.3 & $1001.2 \pm 2.8$ & 0.3 \\
\hline \multirow{2}{*}{$\mathbf{I}(R)$} & 100 & $97.3 \pm 3.9$ & 4.0 & $90.9 \pm 5.0$ & 5.5 & $100.1 \pm 4.2$ & 4.2 \\
\hline & 1000 & $998.6 \pm 2.6$ & 0.3 & $990.5 \pm 3.3$ & 0.3 & $1003.7 \pm 3.3$ & 0.3 \\
\hline \multirow{2}{*}{ II $(S)$} & 100 & $99.8 \pm 1.5$ & 1.5 & $96.2 \pm 3.1$ & 3.2 & $101.4 \pm 3.9$ & 3.8 \\
\hline & 1000 & $1000.0 \pm 1.3$ & 0.1 & $996.1 \pm 3.8$ & 0.4 & $1002.2 \pm 2.9$ & 0.3 \\
\hline \multirow{2}{*}{ II $(R)$} & 100 & $97.9 \pm 2.9$ & 3.0 & $94.3 \pm 4.1$ & 4.3 & $104.2 \pm 3.7$ & 3.6 \\
\hline & 1000 & $998.4 \pm 2.6$ & 0.3 & $991.3 \pm 3.1$ & 0.3 & $1002.7 \pm 2.1$ & 0.2 \\
\hline
\end{tabular}

${ }^{a}$ After $6 \mathrm{~h}$ at room temperature. ${ }^{\mathrm{b}}$ After three freeze and thaw cycles at $-20 \circ \mathrm{C} .{ }^{\mathrm{c}}$ At $-25{ }^{\circ} \mathrm{C}$ for 30 days. ${ }^{\mathrm{d}}$ Values are mean \pm SD for five replicates.

Carry-over was estimated by injecting blank samples after a mixture of analytes. The blank samples injected immediately after the samples containing $1000 \mathrm{ng} / \mathrm{mL}$ of each compound showed no evidence of carry-over.

\subsection{Application of the CE Method for the Quantitation of I (S), I (R) and II (S), II (R) Enantiomers in Real Serum Samples}

The developed CE method was employed in the serum samples to quantify the enantiomers I $(S), \mathbf{I}(R)$, II $(S)$, and II $(R)$ of potential anticancer drugs, which are the new derivatives (I) and (II) of 1,7-diethyl-8,9-diphenyl-4-azatricyclo[5.2.1.0 2,6 ]dec-8-ene-3,5,10trione. Serum taken from healthy volunteers was used as the matrix and spiked with enantiomer standards of compounds (I) and (II). The expected concentration of the particular compounds in patient serum samples was $45 \mu \mathrm{g} / \mathrm{mL}$. The developed method enabled determining the I $(S), \mathbf{I}(R), \mathbf{I I}(S)$, and II $(R)$ compounds at concentrations $216.5 \mathrm{ng} / \mathrm{mL}$, $217.8 \mathrm{ng} / \mathrm{mL}, 217.1 \mathrm{ng} / \mathrm{mL}$, and $218.1 \mathrm{ng} / \mathrm{mL}$ for I $(S), \mathbf{I}(R)$, II $(S)$, and II $(R)$ compounds, respectively. Furthermore, the expected concentration was much higher than the LOD of the developed method, which indicates that the method can be successfully applied for the determination of individual enantiomers of compounds (I) and (II) in serum. 


\section{Conclusions}

This paper described the procedure that uses the dual chiral-achiral selector complex consisting of 2-hydroxypropyl- $\beta$-cyclodextrin and 5,10,15,20-tetrakis (4-hydroxyphenyl) porphyrin in $\mathrm{CE}$ for the concomitant detection of the four enantiomers of anticancer drugs, the newly patented I and II derivatives of 1,7-diethyl-8,9-diphenyl-4-azatricyclo[5.2.1.02,6]dec-8ene-3,5,10-trione. The present study showed that the developed method allows separating a mixture of molecules I $(S), \mathbf{I}(R)$, and II $(S), \mathbf{I I}(R)$, and is stereospecific, accurate and precise, and suitable for studying the pharmacokinetics, bioavailability, and optical purity of these enantiomers. In addition, the method enables a good separation of the enantiomers I $(S), \mathbf{I}(R)$, and II $(S), \mathbf{I I}(R)$, in a very short time, with a lower amount of the injected sample. The single-step method of extraction offers an excellent recovery at a range of $94.6-99.9 \%$. Furthermore, the extraction procedure is easy to perform and time saving, and hence can be used in clinical trial studies. The LOQs were $216.5 \mathrm{ng} / \mathrm{mL}$ for compound I $(S), 217.8 \mathrm{ng} / \mathrm{mL}$ for compound I $(R), 217.1 \mathrm{ng} / \mathrm{mL}$ for compound II $(S)$, and $218.1 \mathrm{ng} / \mathrm{mL}$ for compound II $(R)$. The run time was found to be only 8 min for each sample. Among the three CDs tested as chiral selectors, only 2-hydroxypropyl- $\beta$-cyclodextrin allowed for the separation of I $(S), \mathbf{I}(R)$, and II $(S)$, II $(R)$ enantiomers. The introduction of $5,10,15,20$-tetrakis (4-hydroxyphenyl) porphyrin as the second selector and creation of the dual 2-hydroxypropyl- $\beta$-cyclodextrin and 5,10,15,20-tetrakis (4-hydroxyphenyl) porphyrin chiral-achiral selector system led to a significant improvement in the separation process and sensitivity of the method, and thus allowed achieving very good LODs and determining the enantiomers of compounds (I) and (II).

The porphyrin derivative used in this study most likely creates additional connections with the previously formed complexes of individual enantiomers of compounds I and II with 2-hydroxypropyl- $\beta$-cyclodextrin, creating a kind of additional molecular sieve increasing the molecular weight of the complexes, their absorbance, and resolution.

In addition, the developed CE method was applied in the pilot studies of $\mathbf{I}(S), \mathbf{I}(R)$, II $(S)$, and II $(R)$ enantiomers in the blood serum and yielded great results.

Author Contributions: B.G. conceived of the presented idea. B.G. developed the metod and theory. M.N. delivered the investigated compounds. B.G. conceived and planned the experiments. B.G. carried out the experiments, performed the analytic calculations and wrote the manuscript. All authors have read and agreed to the published version of the manuscript.

Funding: Tis research received no external funding.

Data Availability Statement: Not applicable.

Acknowledgments: The analytical studies were performed in the Chair and Department of Biochemistry and Pharmacogenomics of Medical University of Warsaw (WUM) and financially supported by statutory funds of the WUM in Poland.

Conflicts of Interest: The authors have declared no conflict of interest.

\section{References}

1. Leek, H.; Thunberg, L.; Jonson, A.C.; Öhlèn, K.; Klarkvist, M. Strategy for large-scale isolation of enantiomers in drug discovery. Drug Discov. Today 2017, 22, 133-139. [CrossRef]

2. Phinney, K.; Jackson, J.W.; Sander, L.C. Chiral recognition of functionalized cyclodextrins in capillary electrophoresis. Electrophoresis 2002, 23, 1308-1313. [CrossRef]

3. Escuder-Gilaberta, L.; Martín-Bioscaa, Y.; Medina-Hernándeza, M.J.; Sagradoab, S. Cyclodextrins in capillary electrophoresis: Recent developments and new trends. J. Chromatogr. A 2014, 29, 2-23. [CrossRef]

4. Nguyen, L.A.; He, H.; Pham-Huy, C. Chiral Drugs: An Overview. Int. J. Biomed. Sci. 2006, 2, 85-100. [PubMed]

5. Hytte, J.; Bøgesø, K.P.; Perregaard, J.; Sánchez, C. The pharmacological effect of citalopram resides in the (S)-(+)-enantiomer. J. Neural Transm. Gen. 1992, 88, 157-160. [CrossRef]

6. Patrick, K.S.; Caldwell, R.W.; Ferris, R.M.; Breese, G.R. Pharmacology of the enantiomers of threo-methylphenidate. J. Pharmacol. Exp. Ther. 1987, 241, 152-158.

7. Tanaka, S.; Tajima, M.; Tsukada, M.; Tabata, M.A. Comparative Study on Anti-Inflammatory Activities of the Enantiomers, Shikonin and Alkannin. J. Nat. Prod. 1986, 493, 466-469. [CrossRef] 
8. Tucker, G.T.; Lennard, M.S. Enantiomer specific pharmacokinetics. Pharmacol. Therapeut. 1990, 45, 309-329. [CrossRef]

9. Williams, K.; Lee, E. Importance of Drug Enantiomers in Clinical Pharmacology. Drugs 2012, 30, 333-354. [CrossRef] [PubMed]

10. Lin, C.E.; Chen, K.H. Enantioseparation of phenothiazines in capillary zone electrophoresis using cyclodextrins as chiral selectors. J. Chromatogr. A 2001, 930, 155-163. [CrossRef]

11. Qingfu, Z.; Scriba, G.K.E. Advances in the Use of Cyclodextrins as Chiral Selectors in Capillary Electrokinetic Chromatography: Fundamentals and Applications. Chromatographia 2016, 79, 1403-1435.

12. Lancioni, C.; Keunchkarian, S.; Castells, C.B.; Gagliardi, L.G. Enantiomeric separations by capillary electrophoresis: Theoretical method to determine optimum chiral selector concentration. J. Cromatogr. A 2018, 1539, 71-77. [CrossRef]

13. Fang, L.; Du, Y.; Hu, X.; Luo, L.; Guo, X.; Yu, J. Carboxymethyl $\beta$-cyclodextrin as chiral selector in capillary electrophoresis: Enantioseparation of 16 basic chiral drugs and its chiral recognition mechanism associated with drugs' structural features. Biomed Chromatogr. 2017, 31, 1-7. [CrossRef]

14. Saz, J.M.; Marina, M.L. Recent advances on the use of cyclodextrins in the chiral analysis of drugs by capillary electrophoresis. J. Chromatogr. A 2016, 1467, 79-94. [CrossRef] [PubMed]

15. Fanali, S. Enantioselective determination by capillary electrophoresis with cyclodextrins as chiral selectors. J. Chromatogr. A 2000, 875, 89-122. [CrossRef]

16. Shapovalova, E.N.; Fedorova, I.A.; Ananeva, I.A.; Shpigun, O.A. Macrocyclic Antibiotics as Chiral Selectors in High-Performance Liquid Chromatography and Capillary Electrophoresis. J. Anal. Chem. 2018, 73, 1064-1075. [CrossRef]

17. Oswald, M.T.; Ward, T.J. Enantioseparations with the macrocyclic antibiotic ristocetin a using a countercurrent process in C.E. Chirality 1999, 11, 663-668. [CrossRef]

18. Dixit, S.; Park, J.H. Enantioseparation of basic chiral drugs on a carbamoylated erythromycin-zirconia hybrid monolith using capillary electrochromatography. J. Chromatogr. A 2015, 1416, 129-136. [CrossRef]

19. Lebedeva, M.V.; Prokhorova, A.F.; Shapovalova, E.N.; Shpigun, O.A. Clarithromycin as a chiral selector for enantioseparation of basic compounds in nonaqueous capillary electrophoresis. Electrophoresis 2014, 35, 2759-2764. [CrossRef]

20. Jung, S.D.; Park, H. Penicillin G as a novel chiral selector in capillary electrophoresis. J. Chromatogr. A 2014, 1326, 134-138.

21. Desiderio, C.; Fanali, S. Chiral analysis by capillary electrophoresis using antibiotics as chiral selector. J. Chromatogr. A 1998, 807, 37-56. [CrossRef]

22. Kučerová, G.; Procházková, H.; Kalíková, K.; Tesařová, E. Sulfobutylether- $\beta$-cyclodextrin as a chiral selector for separation of amino acids and dipeptides in chromatography. J. Chromatogr. A 2016, 1467, 356-362. [CrossRef]

23. Li, J.; Yu, T.; Xu, G.; Du, Y.; Liu, Z.; Feng, Z.; Yang, X.; Xi, Y.; Liu, J. Synthesis and application of ionic liquid functionalized $\beta$-cyclodextrin, mono-6-deoxy-6-(4-amino-1,2,4-triazolium)- $\beta$-cyclodextrin chloride, as chiral selector in capillary electrophoresis. J. Chromatogr. A 2018, 1559, 178-185. [CrossRef] [PubMed]

24. Wang, S.; Dai, Y.; Wu, J.; Zhou, J.; Tang, J.; Tang, W. Methoxyethylammonium monosubstituted $\beta$-cyclodextrin as the chiral selector for enantioseparation in capillary electrophoresis. J. Chromatogr. A 2013, 1277, 84-92. [CrossRef] [PubMed]

25. Šesták, J.; Theurillat, R.; Sandbaumhüter, F.A.; Thormann, W. Fundamental aspects of field-amplified electrokinetic injection of cations for enantioselective capillary electrophoresis with sulfated cyclodextrins as selector.s. J. Chromatogr. A 2018, 1558, 85-95. [CrossRef] [PubMed]

26. Dai, Y.; Wang, S.; Zhou, J.; Liu, Y.; Sun, D.; Tang, J.; Tang, W. Cationic cyclodextrin as versatile chiral selector for enantiomeric separation in capillary electrophoresis. J. Chromatogr. A 2012, 1246, 98-102. [CrossRef]

27. Vescina, M.C.; Fermier, A.M.; Guo, Y. Comparing cyclodextrin derivatives as chiral selectors for enantiomeric separation in capillary electrophoresis. J. Chromatogr. A 2002, 973, 187-196. [CrossRef]

28. Duan, J.; He, M.; Hu, B. Chiral speciation and determination of selenomethionine enantiomers in selenized yeast by ligandexchange micellar electrokinetic capillary chromatography after solid phase extraction. J. Chromatogr. A. 2012, 1268, 173-179. [CrossRef]

29. Calderón, C.; Lämmerhofer, M. Chiral separation of short chain aliphatic hydroxycarboxylic acids on cinchonan carbamate-based weak chiral anion exchangers and zwitterionic chiral ion exchanger..s. J. Chromatogr. A 2017, 1487, 194-200. [CrossRef]

30. Qi, L.; Han, Y.; Zuo, M.; Chen, Y. Chiral CE of aromatic amino acids by ligand-exchange with zinc (II)-L-lysine complex. Electrophoresis 2007, 28, 2629-2634. [CrossRef]

31. Kodama, S.; Yamamoto, A.; Aizawa, S.; Honda, Y.; Suzuki, K.; Kemmei, T.; Taga, A. Enantioseparation of $\alpha$-hydroxy acids by chiral ligand exchange CE with a dual central metal ion system. Electrophoresis 2012, 33, 2920-2924. [CrossRef] [PubMed]

32. Schmid, M.G.; Grobuschek, N.; Lecnik, O.; Gübitz, G. Chiral ligand-exchange capillary electrophoresis. J. Biochem. Bioph. Meth. 2001, 48, 143-154. [CrossRef]

33. Jiangab, J.; Muc, X.; Qiaoab, J.; Suad, Y.; Qi, L. New chiral ligand exchange capillary electrophoresis system with chiral amino amide ionic liquids as ligands. Talanta 2017, 175, 451-456. [CrossRef]

34. Chen, Y.; Song, L. Enantioseparation by chiral ligand-exchange capillary electrophoresis. Methods Mol. Biol. $2013,970,393-407$.

35. Zhou, L.; Lin, Z.; Reamer, R.A.; Mao, B.; Ge, Z. Stereoisomeric separation of pharmaceutical compounds using CE with a chiral crown ether. Electrophoresis 2007, 28, 2658-2666. [CrossRef] [PubMed]

36. Kim, E.; Koo, Y.M.; Chung, D.S. Chiral counter-current chromatography of gemifloxacin guided by capillary electrophoresis using (+)-(18-crown-6)-tetracarboxylic acid as a chiral selector. J. Chromatogr. A 2004, 1045, 119-124. [CrossRef] 
37. Kuhn, R. Enantiomeric separation by capillary electrophoresis using a crown ether as chiral selector. Electrophoresis 1999, 20, 2605-2613. [CrossRef]

38. Kuhn, R.; Steinmetz, C.; Bereuter, T.; Haas, P.; Erni, F. Enantiomeric separations in capillary zone electrophoresis using a chiral crown ether. J. Chromatogr. A 1994, 666, 367-373. [CrossRef]

39. Nishi, N.; Kuwahara, Y. Enantiomer separation by capillary electrophoresis utilizing noncyclic mono-, oligo- and polysaccharides as chiral selectors. J. Biochem. Biophys. Met. 2001, 48, 89-102. [CrossRef]

40. Atesa, H.; Younesab, A.A.; Mangelingsa, D.; Heydena, Y.V. Enantioselectivity of polysaccharide-based chiral selectors in polar organic solvents chromatography: Implementation of chlorinated selectors in a separation strategy. J. Pharmaceut. Biomed. 2013, 74, 1-13. [CrossRef]

41. Phinney, K.W.; Sander, L.C. Enantioselective separations in capillary electrophoresis with dextran sulfate as the chiral selector. Anal. Bioanal. Chem. 2003, 375, 763-768. [CrossRef] [PubMed]

42. Nishi, H. Enantiomer separation of basic drugs by capillary electrophoresis using ionic and neutral polysaccharides as chiral selectors. J Chromatogr. A 1996, 735, 345-351. [CrossRef]

43. Haginaka, J. Enantiomer separation of drugs by capillary electrophoresis using proteins as chiral selectors. J. Chromatogr. A 2000, 875, 235-254. [CrossRef]

44. Millot, M.C. Separation of drug enantiomers by liquid chromatography and capillary electrophoresis, using immobilized proteins as chiral selectors. J. Chromatogr. B 2003, 797, 131-159. [CrossRef] [PubMed]

45. Lloyd, D.K.; Li, S.; Ryan, P. Protein chiral selectors in free-solution capillary electrophoresis and packed-capillary electrochromatography. J. Chromatogr. A 1995, 694, 285-296. [CrossRef]

46. Kuran, B.; Krawiecka, M.; Kossakowski, J.; Cieślak, M.; Kaźmierczak-Barańska, J.; Królewska, K.; Nawrot, B. New, Substituted Derivatives of Dicarboximides, Optionally in the Form of Pharmaceutically Approved Salts, and Their Use. PL Patent P-400000, 16 July 2012.

47. Grodner, B.; Łukaszkiewicz, J.; Napiórkowska, M. Determination of the stereoisomers in aqueous medium and serum and validation studies of racemic aminoalkanol derivatives of 1,7-dimethyl-8,9-diphenyl-4-azatricyclo [5.2.1.02,6] dec-8-ene-3,5,10trione, potential new anticancer drugs, by capillary electrophoresis. J. Sep. Sci. 2016, 39, 3246-3253.

48. ICH-Q2 (R1), International Conference on Harmonization, Geneva, 2005. Committee for Medicinal Products for Human Use. In Guideline on Bioanalytical Method Validation; EMEA/CHMP/EWP/192217/2009 Rev. 1 Corr. 2**; European Medicines Agency: Amsterdam, The Netherlands, 2011. 